\title{
Enhanced Detection of Ponceau 4R Food Dye by Glassy Carbon Electrode Modified with Reduced Graphene Oxide
}

\author{
Paloma B. de Moraes, Felipe F. Hudari, João P. Silva and Maria V. B. Zanoni* \\ Instituto de Química, Universidade Estadual Paulista (Unesp), 14800-060 Araraquara-SP, Brazil
}

\begin{abstract}
This paper reports the development of a glassy carbon electrode modified with a reduced graphene oxide (r-GO/GCE) for the determination of the food dye named Ponceau 4R (PNC). The modified sensor presented excellent signal gain in relation to the GCE and GCE modified with graphene oxide besides exhibiting well defined oxidation peaks for PNC at potential of $0.61 \mathrm{~V}$. Through the application of square wave voltammetry using the medium of $0.1 \mathrm{~mol} \mathrm{~L}^{-1}$ Britton-Robinson (BR) buffer ( $\mathrm{pH}$ 5.0), analytical curves were constructed under optimized conditions, where linear regions were found within the range of 0.200 to $20.0 \mu \mathrm{mol} \mathrm{\textrm {L } ^ { - 1 }}$. The limits of detection and quantification were $2.84 \times 10^{-8}$ and $9.46 \times 10^{-8} \mathrm{~mol} \mathrm{~L}^{-1}$, respectively. The sensor was successfully applied towards the determination of PNC in instant juice sample. A comparison made between the result obtained through the application of this sensor and via the high-performance liquid chromatography (HPLC) technique showed no significant difference between the two methods.
\end{abstract}

Keywords: voltammetric sensor, dye, voltammetric determination, electrochemical sensor, electroanalysis

\section{Introduction}

Food colorings are dye additives defined as any substance that confers, enhances or restores food color. They are widely used in the food industry for the enhancement of the aesthetic appeal of processed food. Food dyes are controlled by restrictive legislation worldwide..$^{1-3}$ In Brazil, the current legislation on food dyes is stipulated under Resolutions 382 to 388 of ANVISA (National Agency of Sanitary Surveillance). ${ }^{4}$ The legislation limits the use of only eleven synthetic dyes in foods and beverages, with acceptable daily intake in the range of 0.10 to $15 \mathrm{mg} \mathrm{kg}^{-1}$. Ponceau $4 \mathrm{R}$ (PNC, E124) is an intense red synthetic food colorant found in sweets, powder juices, milk derivatives, among other products. Studies have shown that this food additive is associated with cases of allergies and increasing rates of hyperactivity in children., ${ }^{5,6}$ As a result, its daily intake level allowed by international regulatory agencies is likely to be scaled down. ${ }^{7}$ Considering that great part of these dyes is released from industrial effluents and domestic sewage, these substances are regarded as contaminants of surface waters and drinking water processing plants. ${ }^{8}$

*e-mail: boldrinv@iq.unesp.br
In this unpleasant scenario, analytical methods capable of detecting dyes are conceivably highly required.

The literature reports the use of spectrophotometry, ${ }^{9,10}$ high-performance liquid chromatography (HPLC), ${ }^{11}$ spectrometry, ${ }^{12}$ differential pulse polarography (DPP $)^{13}$ and voltammetry ${ }^{14,15}$ for the determination of Ponceau 4R. Among the aforementioned mechanisms, electrochemical techniques are known to be endowed with crucial properties, such as high sensitivity, selectivity, low cost, simplicity, in addition to speed and capacity of miniaturization. These essential properties render them suitable for the development of new, efficient methods for dye determination. ${ }^{14,16}$ Apart from the interesting and inherent characteristics of voltammetric techniques, one can think of the possibility of modifying the surface of electrodes using specific materials, thus resulting in improvements in the electroactive area, sensitivity, selectivity and catalytic activity. ${ }^{17-21}$

Graphene is a widely explored material useful for developing electrochemical sensors by virtue of its special physicochemical properties including high surface area, excellent conductivity and high mechanical strength. ${ }^{22}$ It is formed by single sheets of carbon bonded together by $\mathrm{sp}^{2}$ bonds. Graphene displays superior performance as electrocatalyst, in addition to better conductivity and 
large surface area compared to other carbon nanotubebased materials. ${ }^{17,23-26}$ Although graphene has demonstrated great applicability in electroanalysis, Jampasa et al. ${ }^{27}$ demonstrated that screen printed carbon electrode modified with reduced graphene oxide can be used for determining Tartrazine (TZ) and Sunset Yellow (SY) dyes in beverages. They obtained linear relationships in the concentration range of 0.01 to $20 \mathrm{mmol} \mathrm{L}^{-1}$ for SY and 0.02 to $20 \mathrm{mmol} \mathrm{L}^{-1}$ for TZ. They reported to have found limits of detection (LOD) of 0.50 and $4.50 \mathrm{nmol} \mathrm{L}^{-1}$ for SY and TZ, respectively.

The present work was conducted under two-fold objectives. First, it used the excellent electrical and electrocatalytic properties of reduced graphene oxide to modify glassy carbon electrode (GCE). Second, it sought to develop a voltammetric method for determining PNC. The method developed was then applied towards the direct determination of PNC in artificial beverage sample without any pretreatment. Our method demonstrated to be in considerable agreement with high-performance liquid chromatography analysis which was used for comparison.

\section{Experimental}

\section{Reagents and equipment}

All reagents used were of analytical grade. $4 \mathrm{mg} \mathrm{mL}^{-1}$ of graphene oxide and Ponceau 4R dye ( $\geq 99.0 \%)$ were supplied by Sigma-Aldrich. Sodium hydroxide was obtained from Synth. The commercial strawberry-flavored artificial powder juice was purchased from a nearby supermarket. The solutions were prepared using ultrapure water (with resistivity above $18 \mathrm{M} \Omega \mathrm{cm}$ ) provided by Milli-Q System (Millipore). The Britton-Robinson (BR) buffer solution was prepared by mixing $0.1 \mathrm{~mol} \mathrm{~L}^{-1}$ of boric acid (Merck), acetic acid (Merck), $o$-phosphoric acid (Merck) and sodium hydroxide (Merck). Standard solution of $0.01 \mathrm{~mol} \mathrm{~L}^{-1}$ of PNC dye was prepared in aqueous medium. Voltammetric measurements were recorded on an Autolab PGSTAT 302N galvanostat/potentiostat controlled by NOVA software with a conventional three electrode system. The $\mathrm{pH}$ measurements were conducted in a TECNOPON mPA $210 \mathrm{pH}$ meter. The morphological and surface characterization of the electrode material was carried out by scanning electron microscopy (SEM) using FEG-SEM of the model JEOL 7500F. Chromatographic analysis was performed using a high-performance liquid chromatography-diode array detector (HPLC-DAD) (Shimadzu, model LC10ATVp) controlled by software CLASS VP.
Preparation of the electrode modified with r-GO

Initially, an aqueous suspension of graphene oxide (GO) of $1.0 \mathrm{mg} \mathrm{mL}^{-1}$ was placed in an ultrasonic bath for $4 \mathrm{~h}$ aiming at promoting exfoliation. Afterwards, $0.2 \mathrm{~mol} \mathrm{~L}^{-1}$ of sodium sulfate solution was added, yielding a suspension of $0.5 \mathrm{mg} \mathrm{mL}^{-1} \mathrm{GO}$ in $0.1 \mathrm{~mol} \mathrm{~L}^{-1}$ of sodium sulfate. The GCE was properly cleaned by sanding various grain sizes prior to being modified. For the GO modification, a drop containing $10 \mu \mathrm{L}$ of the $\mathrm{GO}$ suspension was poured onto the GCE surface, and the electrode was in turn carefully placed in an oven at $50{ }^{\circ} \mathrm{C}$ for $15 \mathrm{~min}$ aiming at drying the modifier. The $\mathrm{r}-\mathrm{GO} / \mathrm{GCE}$ was prepared through the electrodeposition of the previously prepared graphene oxide suspension in a glassy carbon electrode applying a potential of $-1.4 \mathrm{~V}$ for $500 \mathrm{~s}$, forming a stable and reproducible film. ${ }^{28,29}$

After each modification, the sensor was subjected to successive voltammetric cycles ( 15 cycles) in the range of 0.40 to $1.1 \mathrm{~V}$ in $0.1 \mathrm{~mol} \mathrm{~L}^{-1} \mathrm{BR}$ buffer solution at a scan rate of $75 \mathrm{mV} \mathrm{s}^{-1}$ for stabilization of the modified electrode surface.

\section{Analytical procedure}

Measurements were recorded in a $10 \mathrm{~mL}$ electrochemical cell using a conventional system with three electrodes: $\mathrm{Ag} / \mathrm{AgCl}\left(3 \mathrm{~mol} \mathrm{~L}^{-1}\right)$ being the reference electrode, a platinum wire as auxiliary electrode, and GCE with and without modifications as working electrodes. All the voltammograms were obtained transferring $100 \mu \mathrm{mol} \mathrm{L}{ }^{-1}$ of the selected dye in BR buffer under $\mathrm{pH}$ of 7.0. Cyclic voltammograms were obtained using a scan rate of $75 \mathrm{mV} \mathrm{s}^{-1}$. Square wave voltammograms (SWV) were recorded using optimized conditions of accumulation time $(30 \mathrm{~s})$, frequency $(25 \mathrm{~Hz})$, step potential $(10 \mathrm{mV})$ and pulse amplitude (70 mV).

The adherence of Ponceau 4R to the r-GO/GCE film was investigated by the immersion of the modified electrode in a solution ( $\mathrm{pH}$ 5.0) containing Ponceau 4R dye, for $30 \mathrm{~s}$ under stirring. Subsequently, the electrode was washed with pure water and transferred to a voltammetric cell containing $10 \mathrm{~mL}$ of supporting electrolyte $(\mathrm{pH}=5.0)$ and square wave voltammograms were recorded in the range of 0.45 to $0.90 \mathrm{~V}$.

\section{Application of the proposed method}

\section{Analysis of PNC on r-GO/GCE}

$0.1 \mathrm{~g}$ of strawberry flavor artificial powder juice sample was dissolved in $10 \mathrm{~mL}$ of ultra-pure water. $1 \mathrm{~mL}$ of the sample was then transferred to an electrochemical 
cell containing $9 \mathrm{~mL}$ of $0.10 \mathrm{~mol} \mathrm{~L}^{-1}$ BR buffer (pH 5.0). Following the immersion of the electrode in the aforementioned solution for $10 \mathrm{~s}$ under stirring, the electrode was subsequently transferred to a voltammetric cell containing $10 \mathrm{~mL}$ of $0.10 \mathrm{~mol} \mathrm{~L}^{-1} \mathrm{BR}$ buffer ( $\mathrm{pH} 5.0$ ) and analyzed as described in the previous section.

\section{Analysis of PNC by HPLC-DAD}

For HPLC-DAD analysis, $0.5 \mathrm{~g}$ of powder juice sample was dissolved in $50 \mathrm{~mL}$ of ultra-pure water. Quantification of the PNC dye was performed by the standard addition method. The chromatographic measurements were recorded using $\mathrm{C} 18$ column (Phenomenex) with mobile phase consisting of $0.1 \mathrm{~mol} \mathrm{~L}^{-1}$ of (A) ammonia acetate solution ( $\mathrm{pH}$ 8.0) and (B) acetonitrile in gradient mode under the following conditions: $0-4 \mathrm{~min} 5 \% \mathrm{~B}$; 4-10 min $95 \% \mathrm{~B} ; 10-15 \mathrm{~min} 100 \% \mathrm{~B}^{30}$ The flow rate of $1 \mathrm{~mL} \mathrm{~min}^{-1}$ and sample injection volume of $20 \mu \mathrm{L}$ were employed.

\section{Results and Discussion}

\section{Characterization of $r-\mathrm{GO} / \mathrm{GCE}$}

Figures $1 \mathrm{a}$ and $1 \mathrm{~b}$ compare the scanning electron microscopy (SEM) of glassy carbon electrode modified with graphene oxide (GO/GCE) and reduced graphene oxide (r-GO/GCE). While agglomerated blocks are observed in Figure 1a, the surface of the r-GO/GCE (Figure 1b) illustrates a structure of wrinkled sheets owing to the modification that took place after the reduction of graphene oxide. ${ }^{27,31}$

In order to investigate the mechanism by which this chemical structure changes the electroactive area of the electrode, a comparison was made in relation to the electrode active area by recording cyclic voltammograms for $1.00 \mathrm{mmol} \mathrm{L}^{-1}$ potassium hexacyanoferrate(III) solution as model compound (diffusion coefficient $=7.6 \mu \mathrm{cm}^{2} \mathrm{~s}^{-1}$ ) in $0.1 \mathrm{~mol} \mathrm{~L}^{-1} \mathrm{KCl}$ solution for both GCE modified with GO and r-GO. The following Randles-Sevcik equation was applied: ${ }^{32}$

$\mathrm{i}_{\mathrm{pa}}=2.69 \times 10^{5} \mathrm{n}^{\frac{3}{2}} \mathrm{AD}_{0}^{\frac{1}{2}} \mathrm{C}_{0} \mathrm{v}^{\frac{1}{2}}$

where $\mathrm{i}_{\mathrm{pa}}$ is the anodic peak current $(\mu \mathrm{A}), \mathrm{n}$ is the electron number, $\mathrm{A}$ is the electrode active area $\left(\mathrm{cm}^{2}\right), \mathrm{D}_{0}$ is the diffusion coefficient $\left(\mathrm{cm}^{2} \mathrm{~s}^{-1}\right), v^{1 / 2}$ is the scan rate square root $\left(\mathrm{V} \mathrm{s}^{-1}\right)$ and $\mathrm{C}_{0}$ being the analyte concentration $\left.(\mathrm{mol} \mathrm{cm})^{-3}\right)$. The electroactive areas for GCE modified with GO and r-GO/GCE correspond to $1.96 \times 10^{-3}$ and $7.61 \times 10^{-3} \mathrm{~cm}^{2}$, respectively. These results suggest that the simple electrochemical procedure used to produce
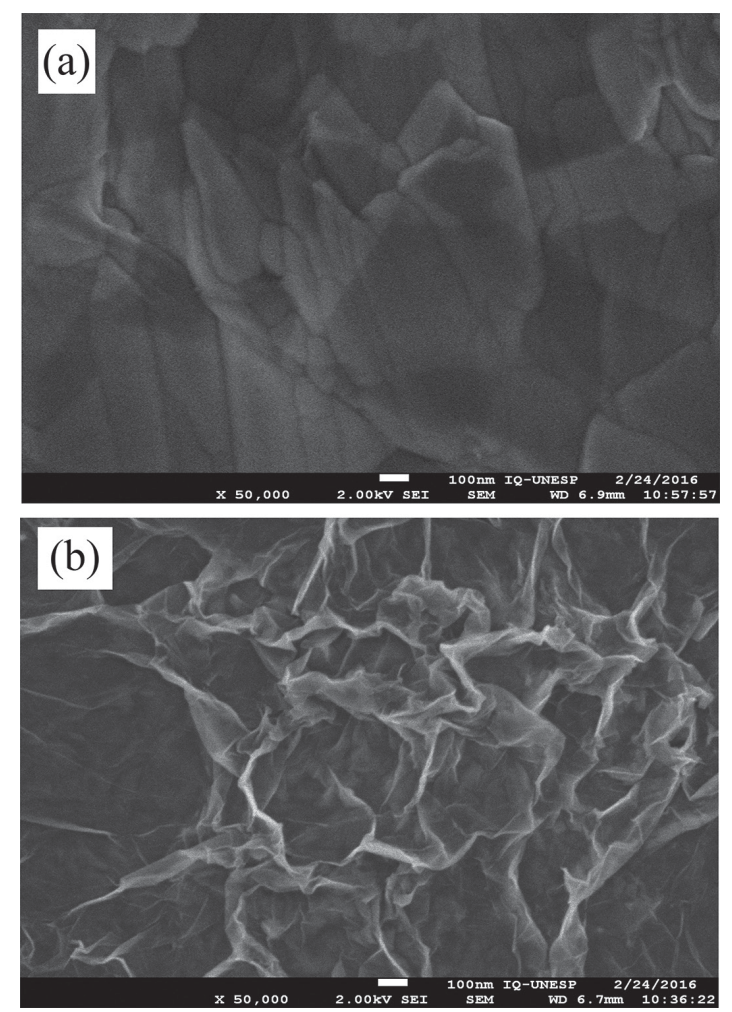

Figure 1. SEM of (a) GO/GCE and (b) r-GO/GCE for 50,000-fold amplification.

the $\mathrm{r}$-GO electrode yielded an increase in surface area of approximately four times bigger compared to the GO/GCE electrode.

\section{Electrochemical oxidation of PNC}

Figure 2 shows cyclic voltammograms recorded for $100 \mu \mathrm{mol} \mathrm{L}^{-1} \mathrm{PNC}$ dye in $0.1 \mathrm{~mol} \mathrm{~L}^{-1} \mathrm{BR}$ buffer ( $\mathrm{pH} 7.0$ ) on GCE (Figure 2a), GO/GCE (Figure 2b) and r-GO/GCE (Figure 2c). For the GCE (Figure 2a), the voltammograms present an oxidation peak at $0.64 \mathrm{~V}$ and a small peak at $0.58 \mathrm{~V}$ in the reverse scan, where the ratio of $\mathrm{i}_{\mathrm{pc}} / \mathrm{i}_{\mathrm{pa}}=0.36$ ( $i_{p c}$ is the cathodic peak current). One will note that the peak displays characteristics of reversible systems with subsequent chemical reactions since the reverse peak undergoes a slight increase at higher scan rates. ${ }^{32}$ When the $\mathrm{GO} / \mathrm{GCE}$ (Figure 2b) is used, electrochemical behavior similar to that of GCE is observed albeit with a decrease in magnitude of the peak. This result can be attributed to the low conductivity of GO, a material that has many $\mathrm{sp}^{3}$ carbons due to the presence of oxide groups (for example, $-\mathrm{COOH}$ and $-\mathrm{OH})$. Interestingly, an excellent performance is observed on the r-GO/GCE. The oxidation peak is shifted to less negative potential $(0.61 \mathrm{~V})$, and a 20 -fold increase is noted in the anodic peak current. In addition, the electrodic process is found to be closer to the reversible process, 
where $\mathrm{i}_{\mathrm{pc}} / \mathrm{i}_{\mathrm{pa}}=0.98$ and the $\mathrm{E}_{\mathrm{pc}}-\mathrm{E}_{\mathrm{pa}}=30.8 \mathrm{mV}\left(\mathrm{E}_{\mathrm{pc}}\right.$ and $\mathrm{E}_{\mathrm{pa}}$ are the cathodic and anodic peak voltages, respectively). ${ }^{32}$ This behavior suggests that fast electron transfer can be occurring as a result of the reconstitution of a large part of the $\mathrm{sp}^{2}$ bonds between carbons, increasing the conductivity of the material while facilitating the electron transfer..$^{33}$ This behavior indicates that probably the hydroxyl group in the dye molecule undergoes oxidation involving two electrons in a reversible system. ${ }^{32}$

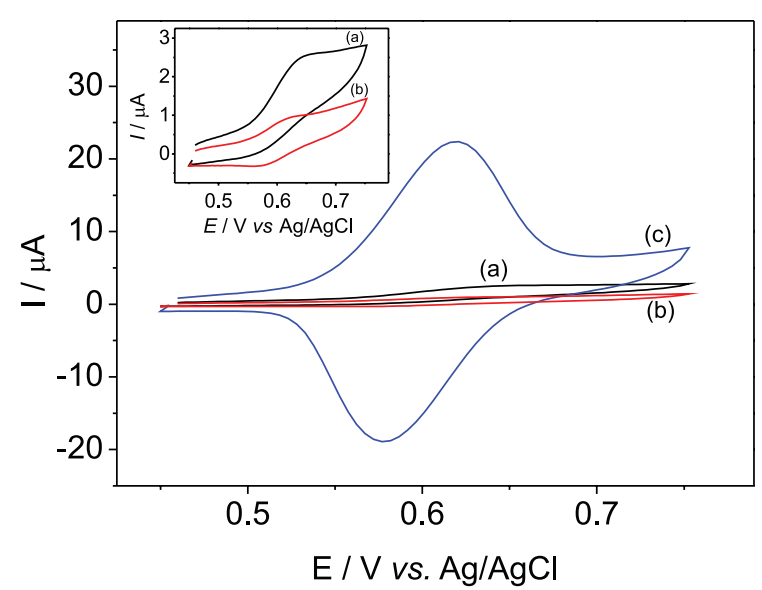

Figure 2. Cyclic voltammograms for $100 \mu \mathrm{mol} \mathrm{L}{ }^{-1}$ of PNC in $0.10 \mathrm{~mol} \mathrm{~L}^{-1}$ buffer BR, pH 7.0 on (a) GCE; (b) GO/GCE and (c) r-GO/GCE. $v=100 \mathrm{mV} \mathrm{s}^{-1}$.

The effect of scan rate on the oxidation was evaluated by recording cyclic voltammograms for $100 \mu \mathrm{mol} \mathrm{L}^{-1}$ of PNC in $0.1 \mathrm{~mol} \mathrm{~L}^{-1} \mathrm{BR}$ buffer (pH 5.0) from 5 to $500 \mathrm{mV} \mathrm{s}^{-1}$. The anodic current is found to increase linearly, with the equation $\mathrm{i}_{\mathrm{pa}}=7.11 \times 10^{-4} \mathrm{v}+3.37 \times 10^{-6}$ (coefficient of determination $\left(R^{2}\right)=0.98, v$ is the scan rate), indicating that the charge transfer is controlled by adsorption process. ${ }^{32}$ Considering that the process is adsorptive, the surface excess $(\Gamma)$ was calculated aiming at verifying the electroactive species concentration on the modified electrode surface using the following equation: ${ }^{32}$

$i_{p a}=\frac{n^{2} F^{2} A \Gamma v}{4 R T}$

where $i_{p a}$ is the anodic peak current, $n$ is the electrons number, $\mathrm{F}$ is the Faraday constant, $v$ is the scan rate, $\mathrm{A}$ is the electrode active area, $\Gamma$ is the electroactive species surface concentration, $\mathrm{R}$ is the gas constant $\left(8.314 \mathrm{~J} \mathrm{~mol}^{-1} \mathrm{~K}^{-1}\right)$ and $\mathrm{T}$ is the temperature. By replacing the values in equation 2 , the concentration of PNC on the surface of $\mathrm{r}-\mathrm{GO} / \mathrm{GCE}$ is found to be $24.9 \mathrm{nmol} \mathrm{cm}$.

\section{Optimization of parameters}

In order to find low levels of PNC dye detection, parameters such as accumulation time, $\mathrm{pH}$ and scanning technique were optimized. Considering that the analyte is strongly adsorbed on the electrode surface, the effect of the accumulation time was studied in the range of 5 to $50 \mathrm{~s}$ aiming at verifying the analyte response. The measurements were recorded for $30 \mu \mathrm{mol} \mathrm{L}-1$ of PNC in $0.1 \mathrm{~mol} \mathrm{~L}^{-1} \mathrm{BR}$ buffer ( $\mathrm{pH}$ 7.0) by cyclic voltammetry $\left(v=100 \mathrm{mV} \mathrm{s}^{-1}\right)$. An increase in the $\mathrm{i}_{\mathrm{pa}}$ of the dye was observed for up to $30 \mathrm{~s}$ of preconcentration $\left(t_{a c}\right.$, accumulation time), while a plateau was noted at longer periods beyond $30 \mathrm{~s}$. In view of that, prior to each measurement, the solution was stirred for $30 \mathrm{~s}$.

The $\mathrm{pH}$ effect on both the oxidation peak and the $i_{\mathrm{pa}}$ of the dye was verified using cyclic voltammetry by varying the $\mathrm{pH}$ of the $0.1 \mathrm{~mol} \mathrm{~L}^{-1} \mathrm{BR}$ buffer between 3 to 10 . The best $\mathrm{i}_{\mathrm{pa}}$ responses were verified for $\mathrm{pH} 5$ and 7. However, a better peak resolution and lower deviation between measurements was observed for $\mathrm{pH} 5$, hence, it was chosen for the performance of other experiments. The relationship between $\mathrm{E}_{\mathrm{pa}} v s$. $\mathrm{pH}$ can be described by the equation $\mathrm{E}_{\mathrm{pa}}=-0.0310 \mathrm{pH}+0.8368\left(\mathrm{R}^{2}=0.990\right)$, which indicates that the ratio of $\mathrm{H}^{+} / \mathrm{e}^{-}$participation in the oxidation reaction of the PNC dye is $1 / 2$, respectively. A proposed PNC oxidation mechanism is shown in Figure 3, which is attributed to the oxidation of phenolic hydroxyl group. ${ }^{34}$

To obtain better results for PNC, the analytical techniques including linear sweep (LSV), differential pulse (DPV) and square wave voltammetry (SWV) were studied for $1 \mu \mathrm{mol} \mathrm{L} \mathrm{L}^{-1}$ of dye in $0.1 \mathrm{~mol} \mathrm{~L}^{-1} \mathrm{BR}$ buffer $(\mathrm{pH} 5.0)$ and $\mathrm{t}_{\mathrm{ac}}=30 \mathrm{~s}$. The best responses were found via SWV, which represented an increase of 369 and $105 \%$ in $\mathrm{i}_{\mathrm{pa}}$ compared to the LSV and DPV techniques, respectively. Hence, SWV parameters such as frequency $(10-100 \mathrm{~Hz})$, step potential $(2-10 \mathrm{mV})$ and pulse amplitude $(20-80 \mathrm{mV})$

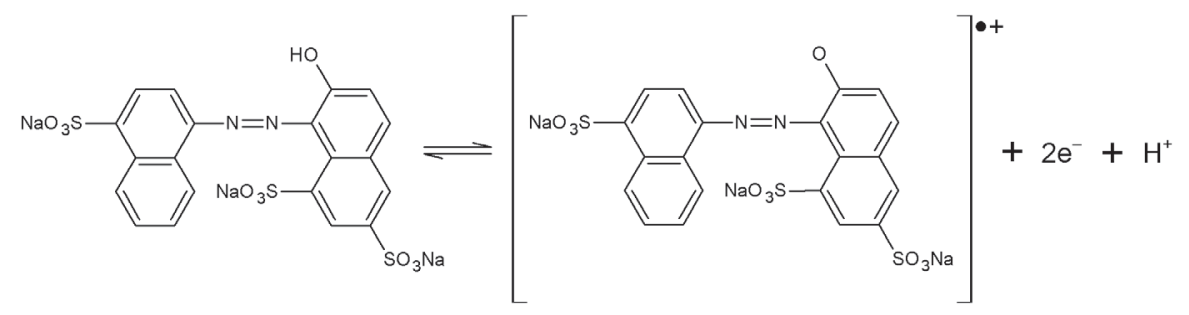

Figure 3. Proposed mechanism for the oxidation reaction of PNC against r-GO/GCE. 
were optimized, where the best conditions were found to be at $25 \mathrm{~Hz}, 10 \mathrm{mV}$ and $70 \mathrm{mV}$, respectively.

\section{Analytical performance}

Under optimized conditions of $\mathrm{t}_{\mathrm{ac}}, \mathrm{pH}$ and SWV, voltammograms were recorded for the PNC dye in $0.1 \mathrm{~mol} \mathrm{~L}^{-1} \mathrm{BR}$ buffer (pH 5.0) (Figure 4). By applying $\mathrm{a}_{\mathrm{ac}}$ of $30 \mathrm{~s}$, a linear relationship was found in the range of 0.200 to $20.0 \mu \mathrm{mol} \mathrm{L} \mathrm{L}^{-1}$ with the following equation: $\mathrm{i}_{\mathrm{pa}}=3.65 \times[\mathrm{PNC}]+2.12 \times 10^{-6}\left(\mathrm{R}^{2}=0.998\right)$ (inset in Figure 4). The limits of detection (LOD) and quantification (LOQ) were calculated using the following equations: LOD $=3 \mathrm{std} / \mathrm{m}$ and LOQ $=10 \mathrm{std} / \mathrm{m}$, where $\mathrm{m}$ and $\mathrm{std}$ stand for angular coefficient and standard deviation of the analytical curve, respectively. The values of LOD and LOQ were $2.84 \times 10^{-8}$ and $9.46 \times 10^{-8} \mathrm{~mol} \mathrm{~L}^{-1}$, respectively.

In Table 1, figures of merit of the proposed method are compared with other methods found in the literature for the determination of PNC. Although the studies reported by Zhang et al., ${ }^{34}$ Zhang et al., ${ }^{35}$ Yang et al..${ }^{36}$ and Wang and $\mathrm{Zhao}^{37}$ presented lower LOD, these methods have a much lower analytical frequency than the proposed method. In addition, the LOD and LOQ of the proposed method are below the values stipulated by the regulatory agencies $(0.10$ to $15 \mathrm{mg} \mathrm{kg}^{-1}$ ).

\section{Selectivity}

For the assessment of the degree of interference of other food colorants in the determination of Ponceau 4R, voltammograms were recorded for $100 \mu \mathrm{mol} \mathrm{L}^{-1}$ of PNC in the presence of Allura Red 40 (V40) and Brilliant Blue FCF $(\mathrm{AB})$ at the same concentration. As depicted in Figure 5,

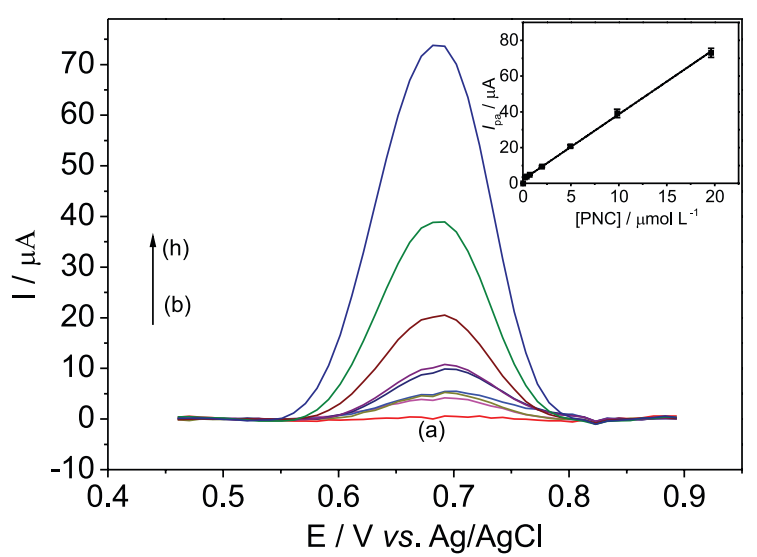

Figure 4. (a) SWV in $0.1 \mathrm{~mol} \mathrm{~L}^{-1} \mathrm{BR}$ buffer ( $\mathrm{pH} \mathrm{5.0)}$ ) at PNC concentrations of (b) 0.200 ; (c) 0.400 ; (d) 0.700; (e) 1.98; (f) 4.93; (g) 9.82 ; (h) $20.0 \mu \mathrm{mol} \mathrm{L} \mathrm{L}^{-1}$. Inserted: relationship between $\mathrm{i}_{\mathrm{pa}} v s$. [PNC] in the intervals between 0.200 to $20.0 \mu \mathrm{mol} \mathrm{L}^{-1}$.

individual voltammograms for dyes V40 (curve b) and $\mathrm{AB}$ (curve c) show anodic peaks at the potentials of 0.75 and $0.91 \mathrm{~V}$, respectively, relative to the dyes oxidation. As can be observed in curve d, the voltammetric profile for the PNC did not show any great difference when analyzed individually (curve a) and when in the presence of the dyes V40 and AB. Clearly, this shows that there is neither overlapping of peaks nor the exertion of influence on the $\mathrm{i}_{\text {ap }}$ even when PNC is in the presence of the dyes under analysis.

\section{Application of the method}

In order to evaluate the applicability of the $\mathrm{r}-\mathrm{GO} / \mathrm{GCE}$ sensor, tap water sample was analyzed. To this end, the tap water sample was fortified with $5.00 \mu \mathrm{mol} \mathrm{L^{-1 }}$ of PNC and analyzed $(\mathrm{n}=3)$ using the standard addition method. The value found for PNC recovery was $5.20 \pm 0.150 \mu \mathrm{mol} \mathrm{L} \mathrm{L}^{-1}$.

Table 1. Comparison of the r-GO/GCE method with other methods reported in the literature regarding the determination of Ponceau

\begin{tabular}{|c|c|c|c|c|}
\hline Electrode & Technique & Concentration range / $\left(\mathrm{mol} \mathrm{L}^{-1}\right)$ & $\mathrm{LOD} /\left(\mathrm{mol} \mathrm{L}^{-1}\right)$ & Reference \\
\hline MWNT/GCE & DPV & $4.13 \times 10^{-8}-2.48 \times 10^{-6}$ & $2.48 \times 10^{-8}$ & 34 \\
\hline IL-EGPE & SWSV & $1.00 \times 10^{-8}-5.00 \times 10^{-6}$ & $1.40 \times 10^{-9}$ & 35 \\
\hline $\mathrm{Cu}-\mathrm{BTC} / \mathrm{CPE}$ & DPV & $2.07 \times 10^{-9}-8.27 \times 10^{-7}$ & $1.08 \times 10^{-9}$ & 36 \\
\hline IL-GO-MWCNT/GCE & SWV & $8.00 \times 10^{-9}-1.50 \times 10^{-7}$ & $6.00 \times 10^{-9}$ & 37 \\
\hline $\mathrm{BFE}$ & DPV & $0-9.93 \times 10^{-5}$ & $1.65 \times 10^{-6}$ & 38 \\
\hline DME & DPP & $0-6.62 \times 10^{-6}$ & $6.28 \times 10^{-8}$ & 39 \\
\hline DME & DPP & $0-4.13 \times 10^{-6}$ & $7.28 \times 10^{-8}$ & 39 \\
\hline DME & DPP & $0-5.79 \times 10^{-6}$ & $7.77 \times 10^{-8}$ & 39 \\
\hline AB-modified GCE & AASV & $8.27 \times 10^{-8}-2.98 \times 10^{-5}$ & $1.65 \times 10^{-7}$ & 40 \\
\hline $\mathrm{r}-\mathrm{GO} / \mathrm{GCE}$ & SWV & $2.00 \times 10^{-7}-9.71 \times 10^{-5}$ & $2.84 \times 10^{-8}$ & this work \\
\hline
\end{tabular}

MWNT/GCE: multi-wall carbon nanotube film-modified glassy carbon electrode; IL-EGPE: ionic liquid modified expanded graphite paste electrode; Cu-BTC/CPE: copper based metal-organic framework modified carbon paste electrode; IL-GO-MWCNT/GCE: ionic liquid-graphene oxides-multi-walled carbon nanotubes modified glassy carbon electrode; BFE: bismuth film electrode; DME: dropping mercury electrode; AB-modified GCE: acetylene black nanoparticle-modified glassy carbon electrode; r-GO/GCE: glassy carbon electrode modified with a reduced graphene oxide; DPV: differential pulse voltammetry; SWSV: square-wave stripping voltammetry; DPP: differential pulse polarography; AASV: adsorptive anodic stripping voltammetry. 


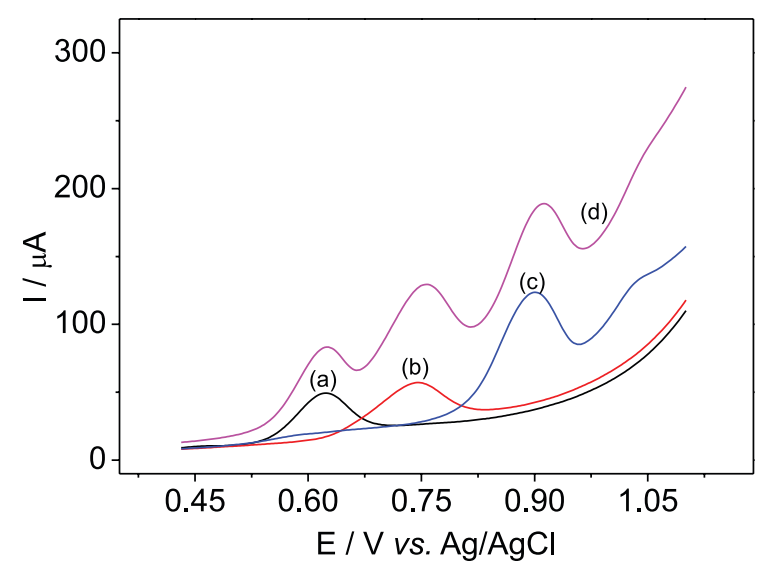

Figure 5. Voltammograms obtained for individual oxidation of $100 \mu \mathrm{mol} \mathrm{L}^{-1}$ of (a) Ponceau 4R; (b) Allura Red 40, (c) Brilliant Blue FCF and (d) in the presence of the three dyes using r-GO/GCE in BR buffer $0.10 \mathrm{~mol} \mathrm{~L}^{-1}, \mathrm{pH} 7.0\left(v=75 \mathrm{mV} \mathrm{s}^{-1}\right)$.

By applying Student's $t$-test, the calculated $t$-value $\left(t_{\text {calc. }}=2.35\right)$ was found to be lower compared to the tabulated $t$-value $\left(t_{\text {tab. }}=4.30\right) .{ }^{41}$ This indicates that there was no significant difference at $95 \%$ confidence level between the fortified and recovered concentrations.

The potential of the proposed sensor was also evaluated using the instant strawberry flavor juice sample containing the dye under investigation. The sample was diluted as described in Application of the proposed method section, and then inserted into an electrochemical cell containing $0.1 \mathrm{~mol} \mathrm{~L}^{-1} \mathrm{BR}$ buffer ( $\mathrm{pH} 5.0$ ), with no previous treatment. Figure $6 \mathrm{~A}$ shows the square wave voltammograms and the standard addition curve constructed (inserted) in the range of 2 to $12 \mu \mathrm{mol} \mathrm{L} \mathrm{L}^{-1}$ with the aim of determining the sample concentration. The concentration of the PNC dye found in the instant juice sample was $29.8 \pm 2.52 \mu \mathrm{mol} \mathrm{L}^{-1}$ per gram of sample.

The method was compared to the HPLC-DAD technique using optimized conditions as described in Analysis of PNC by HPLC-DAD section. As PNC shows maximum absorbance at $509 \mathrm{~nm}$, the chromatographic analysis was carried out monitoring this wavelength. The sample was not subjected to any pre-treatment prior to performing the chromatographic analysis. Figure 6B presents the chromatogram obtained for a sample doped with $4 \mu \mathrm{mol} \mathrm{L} \mathrm{L}^{-1}$ of PNC and under chromatographic conditions optimized in this work. The PNC retention time observed was $7.65 \mathrm{~min}$ (Figure 6B).

Table 2 shows the concentrations of PNC in the sample for both methods, where proximity is observed between them.

With the aid of the Student's $t$-test (paired $t$-test), 0.207 was found for the $t_{\text {calc. }}$, which is lower than the $t_{\text {tab. }}$ value (4.30). This result demonstrates that the concentration found in the instant juice sample via the proposed method
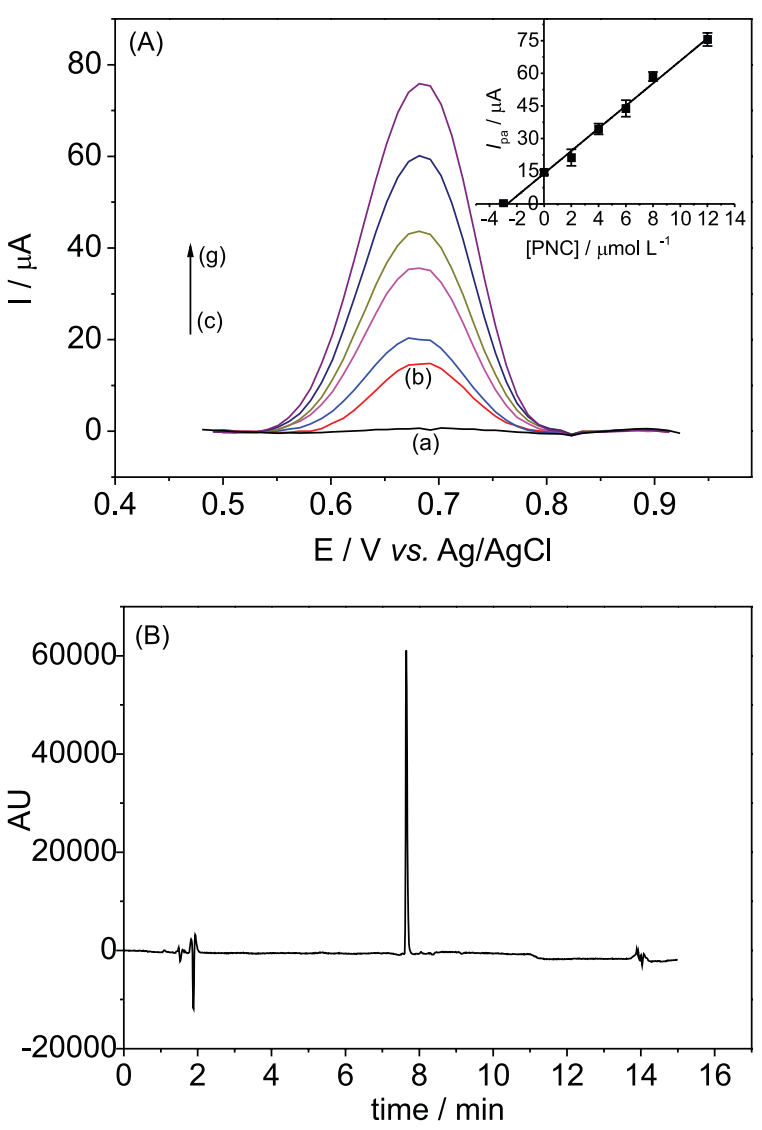

Figure 6. (A) Square-wave voltammograms on $\mathrm{r}-\mathrm{GO} / \mathrm{GCE}$ in (a) $0.10 \mathrm{~mol} \mathrm{~L}^{-1}$ of BR buffer (pH 5.0); (b) $1 \mathrm{~mL}$ of diluted sample and successive additions of PNC: (c) 2.0; (d) 4.0; (e) 6.0; (f) 8.0 and (g) $12 \mu \mathrm{mol} \mathrm{L}{ }^{-1}$. Inserted: standard addition curve constructed by the two analytical cells method via adsorption (Analysis of PNC on r-GO/GCE section); (B) chromatogram obtained for a sample doped with $4 \mu \mathrm{mol} \mathrm{L}{ }^{-1}$ of PNC.

Table 2. Determination of strawberry flavor juice sample by the r-GO/GCE method and HPLC-DAD technique $(n=3)$

\begin{tabular}{lcc}
\hline Method & r-GO/GCE & HPLC-DAD \\
\hline $\begin{array}{l}\text { Found values / } \\
\text { ( } \begin{array}{ll}\text { mol L } \\
\text {-1 per } \text { gram of sample) }\end{array}\end{array}$ & $29.8 \pm 2.52$ & $29.7 \pm 0.643$ \\
\hline
\end{tabular}

r-GO/GCE: glassy carbon electrode modified with a reduced graphene oxide; HPLC-DAD: high performance liquid chromatography-diode array detector.

showed no significant difference at $95 \%$ confidence level compared to the HPLC-DAD method.

\section{Conclusions}

The sensor based on glassy carbon electrode modified with reduced graphene oxide proved to be an excellent alternative for the determination of Ponceau 4R food colorant in instant juice sample. Through the reduction of graphene oxide, it was possible to attain a significant 
gain in the analyte signal, which paved the way towards the determination of the PNC dye at low levels of concentration. In addition, the sensor did not show interference in the analyte response irrespective of the presence of Allure Red 40 and Brilliant Blue FCF. The proposed method applied for the determination of PNC in juice sample was compared to the HPLC-DAD technique. The results showed no significant difference between the two methods at $95 \%$ confidence level.

\section{Acknowledgments}

The authors gratefully acknowledge the financial support granted by CNPq (grant numbers 153169/2014-1 and 446245/2014-3) and Fapesp (grant number 2015/18109-4) during the course of this research. FEG-SEM facilities were provided by LMA-IQ.

\section{References}

1. Agência Nacional de Vigilância Sanitária (ANVISA), Resolução CNNPA No. 44, de 1977, DOU, seção I, 01/02/78 e 24/04/78, Brazil. Available at http://www.anvisa.gov.br/anvisalegis/ resol/44_77.htm, accessed in November 2017.

2. Food and Agriculture Organization of the United Nations (FAO); Chemical Risks and JECFA; available at http://www.fao.org/ food/food-safety-quality/scientific-advice/jecfa/, accessed in June 22, 2017.

3. ht tp://eur-lex.europa.eu/legal-content/EN/ TXT/?uri=uriserv\%3Asa0003, accessed in June 22, 2017.

4. Agência Nacional de Vigilância Sanitária (ANVISA); Resolução No. 388, de 05 de agosto de 1999, Aprova o "Regulamento Técnico que Aprova o Uso de Aditivos Alimentares, Estabelecendo suas Funções e seus Limites Máximos para a Categoria de Alimentos 19 - Sobremesas”; D.O.U.; Poder Executivo, de 09 de agosto de 1999. Available at http://portal.anvisa.gov.br/documents/33916/391619/ RESOLUCAO_388_1999.pdf/ac1c03bc-17b8-46a1-b8e51003d3a930d8, accessed in June 22, 2017.

5. Oliveira, D. F. M.; Batista, P. S.; Muller, P. S.; Velani, V.; França, M. D.; de Souza, D. R.; Machado, A. E. H.; Dye Pigm. 2012, $92,563$.

6. Thiam, A.; Brillas, E.; Centellas, F.; Cabot, P. L.; Sirés, I.; Electrochim. Acta 2015, 173, 523.

7. Arnold, L. E.; Lofthouse, N.; Hurt, E.; Neurotherapeutics 2012 , 9, 599.

8. Sarıkaya, R.; Selvi, M.; Erkoç, F.; Chemosphere 2012, 88, 974.

9. Altınöz, S.; Toptan, S.; J. Food Compos. Anal. 2003, 16, 517.

10. Sayar, S.; Özdemir, Y.; Food Chem. 1998, 61, 367.

11. Sadeghi, S.; Hemmati, M.; Garmroodi, A.; Electroanalysis 2013, 25, 316.
12. Tikhomirova, T. I.; Ramazanova, G. R.; Apyari, V. V.; Food Chem. 2017, 221, 351.

13. Chanlon, S.; Joly-Pottuz, L.; Chatelut, M.; Vittori, O.; Cretier, J. L.; J. Food Compos. Anal. 2005, 18, 503.

14. Zhang, J.; Wang, M.; Shentu, C.; Wang, W.; Chen, Z.; Food Chem. 2014, 160, 11.

15. Huang, J.; Zeng, Q.; Wang, L.; Electrochim. Acta 2016, 206, 176.

16. Chao, M.; Ma, X.; Food Anal. Methods 2015, 8, 130.

17. Mazloum-Ardakani, M.; Rajabzadeh, N.; DehghaniFirouzabadi, A.; Benvidi, A.; Mirjalili, B. B. F.; Zamani, L.; J. Electroanal. Chem. 2015, 760, 151.

18. Motaharian, A.; Milani Hosseini, M. R.; Lima, J. L. F. C.; Kohlhaas, K. A.; Kleinhammes, A.; Jia, Y.; Wu, Y.; Nguyen, S. T.; Ruoff, R. S.; Anal. Methods 2016, 8, 6305.

19. Shang, L.; Zhao, F.; Zeng, B.; Food Chem. 2014, 151, 53.

20. Hudari, F. F.; de Almeida, L. C.; da Silva, B. F.; Zanoni, M. V. B.; Microchem. J. 2014, 116, 261.

21. Hudari, F. F.; da Silva, B. F.; Pividori, M. I.; Zanoni, M. V. B.; J. Solid State Electrochem. 2016, 20, 2491.

22. Shao, Y.; Wang, J.; Wu, H.; Liu, J.; Aksay, I.; Lin, Y.; Electroanalysis 2010, 22, 1027.

23. Wang, Y.; Li, Y.; Tang, L.; Lu, J.; Li, J.; Electrochem. Commun. 2009, 11, 889.

24. Alwarappan, S.; Erdem, A.; Liu, C.; Li, C.-Z.; J. Phys. Chem. C 2009, 113, 8853.

25. Liu, Y.; Dong, X.; Chen, P.; Chem. Soc. Rev. 2012, 41, 2283.

26. Xu, Y.; Gao, H.; Li, M.; Guo, Z.; Chen, H.; Jin, Z.; Yu, B.; Nanotechnology 2011, 22, 365202.

27. Jampasa, S.; Siangproh, W.; Duangmal, K.; Chailapakul, O.; Talanta 2016, 160, 113.

28. Hilder, M.; Winther-Jensen, B.; Li, D.; Forsyth, M.; MacFarlane, D. R.; Phys. Chem. Chem. Phys. 2011, 13, 9187.

29. Hudari, F. F.; Zanoni, M. V. B.; Microchim. Acta 2017, 184, 4117.

30. Zaijun, L.; Xiulan, S.; Qianfang, X.; Ruiyi, L.; Yinjun, F.; Shuping, Y.; Junkang, L.; Electrochim. Acta 2012, 85, 42.

31. Hudari, F. F.; Costa Ferreira, S. L.; Zanoni, M. V. B.; Electroanalysis 2016, 28, 1085.

32. Bard, A. J.; Faulkner, L. R. In Electrochemical Methods: Fundamentals and Applications; Wiley: New York, 2001, p. 226-260.

33. Kucinskis, G.; Bajars, G.; Kleperis, J.; J. Power Sources 2013 , 240,66 .

34. Zhang, Y.; Zhang, X.; Lu, X.; Yang, J.; Wu, K.; Food Chem. 2010, 122, 909.

35. Zhang, J.; Wang, X.; Zhang, S.; Wang, W.; Hojo, M.; Chen, Z.; J. Electrochem. Soc. 2014, 161, H453.

36. Yang, X.; Sun, D.; Zeng, R.; Guo, L.; Wu, K.; J. Electroanal. Chem. 2017, 794, 229.

37. Wang, M.; Zhao, J.; J. Electrochem. Soc. 2015, 162, H321. 
38. Claux, B.; Vittori, O.; Electroanalysis 2007, 19, 2243.

39. Combeau, S.; Chatelut, M.; Vittori, O.; Talanta 2002, 56, 115.

40. Yang, X.; Qin, H.; Gao, M.; Zhang, H.; J. Sci. Food Agric. 2011, $91,2821$.
41. Miller, J. C.; Miller, J. N.; Statistics for Analytical Chemistry, $2^{\text {nd }}$ ed.; Ellis Horwood Limited: England, 1988.

Submitted: August 25, 2017

Published online: December 5, 2017 